\title{
SAÚDE MENTAL NO TRABALHO: CONTRADIÇÕES E LIMITES*
}

\author{
Amanda de Vasconcelos \\ Centro Universitário Positivo - UnicenP, Curitiba, Brasil \\ José Henrique de Faria \\ Universidade Federal do Paraná, Curitiba, Brasil
}

\begin{abstract}
RESUMO: Ao longo do desenvolvimento do capitalismo, a concepção do que seja a saúde do trabalhador modificouse, passando do patamar da 'preocupação com a sobrevivência do corpo' para a 'preocupação com a saúde mental do trabalhador'. A gestão da saúde foi sendo incorporada às novas formas de gestão dos empreendimentos capitalistas, mas a despeito disso, o sofrimento no trabalho continua, expresso em manifestações como estresse, fadiga crônica, burnout, DORT etc. Este artigo busca identificar e analisar, através de um estudo de caso, as contradições existentes acerca das estratégias organizacionais adotadas sobre Saúde Mental no Trabalho, tendo como referência a percepção dos trabalhadores. Os resultados mostraram que os programas de saúde são baseados em intervenções pontuais, paliativas e estão relacionados ao sistema de controle da organização atuando em cima dos efeitos da organização do trabalho, não se baseando numa real preocupação com a saúde do trabalhador.
\end{abstract}

Palavras-chave: Saúde mental no trabalho; psicopatologia; relações sociais de produção.

\section{MENTAL HEALTH AT WORK: CONTRADICTIONS AND LIMITS.}

ABSTRACT: Along the capitalism development, the conceptions of worker's health has changed, passing from the "preoccupation with the surviving of the body" to the "preoccupation with the worker's mental health". Management of health has been incorporated to the new capitalist enterprising management forms, but in spite of that, the suffering of the worker goes on, expressed in physical manifestations like stress, and chronicle fatigue, burnout and DORT. This essay tries to identify and analyze, through a case study, the existing contradictions about the organizational strategies adopted on mental health at work/labor, having as a reference the workers' perception. The results show that health programs are based in ad hoc and palliative interventions related to the control system of the organization, acting on the effects of work organization, and not based on a real preoccupation with the worker's health.

KEY WORDS: mental health at work/labor, psychopathology, production social relationships.

\section{Introdução}

A compreensão da relação entre trabalho e Saúde Mental tem sido, há várias décadas, objeto de estudo de pesquisadores das áreas de psicologia, psiquiatria, antropologia, sociologia, administração, entre outros. Essas pesquisas tiveram início nos anos 50 com o estudo de Lê Guillant (1954) e Sivadon $(1952,1957)$ sobre as afecções mentais que poderiam ser ocasionadas pelo trabalho. $\mathrm{Na}$ década de 1980, Christophe Dejours, psiquiatra francês, introduziu uma nova teoria sobre a relação entre trabalho e o sofrimento psíquico. Pesquisas que buscavam encontrar doenças mentais caracterizadas em operários semiqualificados evidenciaram não doenças mentais clássicas, mas fragilizações que favoreciam o surgimento de doenças do corpo. Além disso, constataram-se comportamentos estranhos, paradoxais (estratégias defensivas) e consumo de bebidas alcoólicas (Dejours, 1992). Esse novo modelo teórico passou a ser chamado de "Psicodinâmica do Trabalho", uma vez que pretendia estudar as dinâmicas da relação do sujeito com a organização do trabalho que podem gerar fragilizações mentais. Tal modelo recusa as análises baseadas na previsão de causas de doenças a partir de determinadas ocupações.

Para além das condições de trabalho, as pesquisas mostraram que pressões eram decorrentes da organização do trabalho (divisão das tarefas, repetição, cadência, hierarquia, comando, controle). Para Dejours (1992), as condições de trabalho têm como alvo o corpo, enquanto que a organização do trabalho atinge o funcionamento psíquico ${ }^{1}$.

A organização do trabalho pode apresentar-se como fator de fragilização mental dos indivíduos, o que torna as organizações como parte responsável pela Saúde Mental de seus integrantes. De acordo com os dados divulgados pela Fundacentro (2007), entre 2000 e 2005 foram 
registradas 144.789 doenças relacionadas ao trabalho, e pesquisas do Laboratório de Saúde do Trabalhador da Universidade de Brasília demonstram um aumento de $260 \%$ do número de afastamentos por doenças mentais entre os anos de 2000 a 2006. Atualmente, 83 mil brasileiros se afastam do trabalho todo ano por problemas de Saúde Mental. Em 2006, os transtornos de humor representaram o segundo motivo de ausência de trabalho e, nesse mesmo ano, o custo do Instituto Nacional do Seguro Social (INSS) com auxílio-doença para quem sofria de transtornos neuróticos e relacionados ao estresse foi de R \$ 90 milhões (Mello, 2008).

$\mathrm{O}$ aumento do número de registro de doenças relacionadas ao trabalho a cada ano instiga os pesquisadores a investigar a relação entre o surgimento de doenças (físicas, mentais ou psicossomáticas) e a organização do trabalho e as modificações nas relações sociais de produção, principalmente a partir da década de 1970. Muitas mudanças ocorreram a partir desta data, entre elas: revolução tecnológica, interdependência global das sociedades econômicas e políticas, reestruturação produtiva (gestão flexível, formação de redes, fusões, incorporações etc.), o capital financeiro circulando com mais desenvoltura, geração de um novo sistema de comunicação digital, entre outras (Faria, 2004a).

Essas mudanças geradas pelo globalismo e pela abertura econômica influenciaram tanto as pessoas e a sociedade quanto as organizações que precisaram transformar suas estruturas, suas atividades e seus processos para continuarem competitivas e se adaptarem à nova dinâmica do mercado mundial.

Atualmente, as práticas de Saúde Mental nas organizações coexistem com uma pressão por produtividade crescente, num ambiente extremamente competitivo, no qual o indivíduo deve estar sempre pronto para mudar e se adaptar às demandas do mercado. Nesse sentido, podese perguntar: quais as relações entre a Saúde Mental do trabalhador e as demandas organizacionais, especialmente as que exigem maior produtividade, agilidade, perfeição, criatividade e atualização constante?

A partir dessas indagações, tem-se como objetivo principal deste artigo analisar, através de um estudo de caso, as contradições e os limites na Saúde Mental do Trabalho através de uma análise crítica das estratégias organizacionais de enfrentamento das questões relativas ao sofrimento psíquico e às manifestações de psicopatologias. Adicionalmente, pretende-se analisar a percepção dos trabalhadores acerca da relação entre Saúde Mental e organização do trabalho e acerca dos programas de saúde adotados pela organização em estudo.

Este artigo está embasado na psicodinâmica do trabalho, compreendendo-se que a doença mental é resultado da dinâmica da relação do sujeito com a organização do traba- lho. Não se pretende, portanto, realizar análises epidemiológicas, probabilísticas ou relações de causa efeito.

\section{Metodologia}

Os dados apresentados neste artigo são resultado de um estudo de caso em uma organização empresarial de grande porte, que atua, entre outros, no setor educacional. Para esta pesquisa foi escolhido o setor de educação de ensino superior. A escolha desse setor deveu-se ao fato de que no levantamento bibliográfico não se encontraram referências que tratassem da Saúde Mental na perspectiva abordada. E porque se tratando de uma instituição educacional, a relação entre o que se pratica e o que se ensina permite a revelação de contradições. A relevância da escolha da organização, que aqui será denominada Vitis ${ }^{2}$, se deu por se tratar de uma organização de importância econômica no cenário brasileiro, sendo uma das maiores instituições educacionais privadas nacionais. A pesquisa foi realizada no período compreendido entre junho e dezembro de 2006 e seguiu as normas próprias da pesquisa qualitativa (Flick, 2007; Grubits \& Noriega, 2004; Rey, 2005) aplicada a estudo de caso (Yin, 1987). Os discursos (entrevistas, documentos, informativos etc.) foram analisados segundo a concepção da Análise Crítica do Discurso 3 (Fairclouch, 2001). Os métodos utilizados para a obtenção dos dados foram: observação nãoparticipante e entrevistas semi-estruturadas com 30 (trinta) funcionários no total, das áreas técnico-administrativas, gestão administrativa e gestão acadêmica, escolhidos intencionalmente pela relevância de suas contribuições à pesquisa e pela acessibilidade. A população-alvo é formada por empregados que possuem vínculo permanente com a organização, ou seja, que dedicam 40 (quarenta) horas semanais de suas atividades à mesma. As jornadas parciais não foram incluídas porque os reflexos da Saúde Mental poderiam não ter origem na organização estudada. A inclusão de sujeitos que não mantém vínculo permanente com a organização pesquisada na seleção dos entrevistados poderia levar a uma distorção na análise, remetendo a conclusões inadequadas. Na realidade, a pesquisa não buscou analisar as atividades (fim ou meio/ apoio), mas sim a gestão de saúde da organização.

Além das fontes primárias, foram utilizados, como fonte secundária, documentos internos, programas e informativos.

As entrevistas foram transcritas e analisadas individualmente e posteriormente em conjunto. Objetivou-se com isso identificar a percepção dos trabalhadores e gestores sobre o sofrimento próprio e o alheio, sobre a relação da incidência de psicopatologias com o modo de gestão da organização e sobre a gestão de saúde adotada pela organização. 


\section{Contexto geral da Saúde Mental no Trabalho}

As modificações na sociedade e nas relações sociais de produção, no decorrer do desenvolvimento do capitalismo, foram acompanhadas de mudanças nas manifestações de sofrimento e psicopatologia nos indivíduos. De acordo com o Manual de Procedimentos para os Serviços de Saúde do Ministério da Saúde (Brasil, 2001), no Brasil coexistem múltiplas situações de trabalho caracterizadas por diferentes estágios de incorporação de tecnologia, diversas formas de organização e gestão, relações e formas de contrato de trabalho que se refletem sobre a saúde do trabalhador. O processo de reestruturação produtiva, a partir da década de 1990, com a adoção de novas tecnologias, métodos gerenciais e precarização das relações de trabalho (Faria, 2004a), trouxe conseqüências ainda pouco conhecidas sobre a Saúde Mental do trabalhador, expressas através de "novas" doenças como, por exemplo, o Burnout e a LER/DORT".

De acordo com o Ministério da Saúde (Brasil, 2001), os transtornos mentais e do comportamento relacionados ao trabalho são resultado de contextos de trabalho em interação com o corpo e o aparato psíquico dos trabalhadores. Entre os contextos geradores de sofrimento estão: (a) a falta de trabalho ou a ameaça de perda de emprego; (b) o trabalho desprovido de significação, sem suporte social, não reconhecido; (c) situações de fracassos, acidente de trabalho ou mudança na posição hierárquica; (d) ambientes que impossibilitam a comunicação espontânea, manifestação de insatisfações e sugestões dos trabalhadores em relação à organização; (e) fatores relacionados ao tempo, o ritmo e o turno de trabalho; (f) jornadas longas de trabalho, ritmos intensos ou monótonos, submissão do trabalhador ao ritmo das máquinas; (g) pressão por produtividade; (h) níveis altos de concentração somada com o nível de pressão exercido pela organização do trabalho e (i) a vivência de acidentes de trabalho traumáticos.

A relação específica dos transtornos mentais e do comportamento relacionados ao trabalho (Brasil, 2001) conta, hoje, com 12 grupos de doenças mentais, dentre as quais se destacam o alcoolismo crônico, episódios depressivos, estados de estresse pós-traumáticos, neurastenia (síndrome da fadiga crônica), neurose profissional, transtornos do sono e sensação de estar acabado (síndrome de burnout e a síndrome do esgotamento profissional).

\section{Saúde Mental no Trabalho: do Sofrimento à Psicopatologia}

As dificuldades em torno do termo Saúde Mental se devem a duas razões, segundo Borges e Angolo (2003): (a) a diversidade de paradigmas geradores de interpretação e que dificulta a integração entre os modelos explicativos e (b) o revestimento moral que acompanha os conceitos de Saúde Mental, geralmente fundados nos valores das classes dominantes de uma sociedade, mais especificamente, no caráter de exclusividade do modelo médico de avaliação da Saúde Mental.

Esses autores apontam para dois grandes grupos de concepções acerca da Saúde Mental: (a) aquelas que enfatizam a ausência de enfermidades e (b) as outras que ressaltam a presença de componentes positivos. Em geral, a definição de Saúde Mental, do ponto de vista clínico, se dá pela presença ou não de sintomas que classificam uma situação de mau funcionamento psíquico com alterações da personalidade, do pensamento, da percepção, da memória, da inteligência, entre outras.

Embora a presença de sintomas se mostre como condição necessária para detectar uma doença mental, sua ausência não significa a constatação de Saúde Mental. Portanto, é preciso ir além da aparência do fenômeno para que se possa "escutar" o mal-estar, o sofrimento no qual ainda não há doença manifesta. Dessa forma, esta pesquisa propôs-se a escutar o sujeito trabalhador e sua concepção acerca da Saúde Mental, através de sua própria relação com o trabalho e com a organização.

A análise das entrevistas revelou que o tema não é corrente em programas formais da organização, nem mesmo nos grupos e conversas informais, sendo que alguns entrevistados, inclusive, sequer tinham pensado sobre a "Saúde Mental no Trabalho".

A maioria dos entrevistados relacionou Saúde Mental a um equilíbrio psicológico em função de: conforto para trabalhar, tranqüilidade para trabalhar, volume de cobranças razoável, trabalhar sem medo, fazer o que gosta, trabalhar sem pressão, não estar esgotado.

Outros entrevistados relacionaram a Saúde Mental mais especificamente à questão dos relacionamentos com colegas, clientes e na relação hierárquica. Apenas dois entrevistados relacionaram a Saúde Mental no trabalho a atitudes do próprio indivíduo.

Apesar de respostas diferentes em relação ao conhecimento sobre Saúde Mental, todos os entrevistados afirmaram que o trabalho pode influenciar, prejudicar ou aumentar o sofrimento e possíveis adoecimentos mentais ou psicossomáticos. Esses podem ser propiciados através dos seguintes fatores: estresse; fofocas; condições físicas de trabalho inadequadas; relacionamento difícil com a chefia, com subordinados, colegas, clientes ${ }^{5}$; insatisfação com o trabalho; falta de reconhecimento; pressão; responsabilidades; sensação de ser vigiado e orientações contraditórias para a execução da tarefa. Notou-se, durante as entrevistas, que as respostas dos entrevistados sobre o conceito de Saúde Mental estavam diretamente relacionadas a situações de sofrimento pelas 
quais esses sujeitos estavam passando. Dentre os fatores mencionados acima, o mais comentado por todos foi o que se refere às dificuldades de relacionamento entre níveis hierárquicos e com os clientes. As considerações do Entrevistado 25 representam bem o conjunto dos discursos dos demais entrevistados.

Um problema que a gente tem aqui e tem a ver com Saúde Mental e que eu sei que escuto, é a relação funcionário - cliente, que eu acho muito desgastante, eles reclamam, tem dias que gera um desgaste muito grande porque não acatam o que eles falam, debocham da cara deles, humilham, ofendem, eu acho que isso é um problema geral da nossa equipe. Esse seria o maior estressor, além da supervisão muito em cima. Eu vejo isso aqui. Até acho que o objetivo não é "pegação" de pé, é a forma da pessoa trabalhar, de fazer o acompanhamento e às vezes a forma de abordar, de falar com a pessoa eu acho que isso a gente tem aqui que causa um desgaste emocional, e eu diria para você que vai mais longe, às vezes você causa bloqueio nas pessoas.

Esse relato mostra que os relacionamentos, principalmente os que envolvem relações de poder, causam sofrimento para os sujeitos. Na relação com o cliente, a Vitis busca um atendimento de excelência, rápido, eficaz, evitando qualquer tipo de reclamação. De acordo com um dos gestores, "o objetivo é de perfeição".

Dos treinamentos promovidos pela organização, o mais frequiente é sobre "A excelência do atendimento ao cliente", no qual são ensinados macetes de atendimento, postura, enfrentamento do estresse, entre outros. Exigese do funcionário comportamento padronizado, sem falhas, no qual a relação é de obediência à hierarquia e pouco espaço para expressão.

Nesse contexto de trabalho, o sujeito tem seus sentimentos reprimidos, sua agressividade contida, gerando o que Dejours, Abdoucheli e Jayet (1994) chamam de "repressão pulsional", ou seja, repressão do funcionamento psíquico do sujeito, no qual a tarefa esteriotipada, sem o uso da criatividade e da fantasia, torna-se desprovida de significação para o trabalhador. Quando a tarefa executada é compartimentada, é separada da concepção e demanda rigidez na condução, o trabalhador tende a eliminar o sofrimento criativo (imaginação, fantasias etc.) preenchendo sua consciência, muitas vezes, com uma aceleração do ritmo de trabalho. Não é sem razão que os casos de LER/DORT, apesar de não serem doenças novas, tenham apresentado uma incidência epidemiológica nas organizações contemporâneas. "A repressão da pulsão que não se faz representar no aparelho psíquico encontra freqüentemente descarga direta no corpo e, portanto, em doenças físicas" (Hallack \& Silva, 2005, p. 76).

Os entrevistados relataram que a exigência da organização em relação atendimento ao cliente é muito grande. Segundo os entrevistados, é preciso ser competente, ter habilidade e "jogo de cintura" para lidar com clientes difíceis, mal-educados, agressivos, mas não há, na maioria dos setores, nenhum apoio para o funcionário, seja no sentido de autonomia para resolver as situações, seja no sentido de uma defesa contra agressões morais sofridas pelos trabalhadores. Assim, ainda de acordo com a avaliação dos entrevistados, os funcionários fazem o possível para que nenhum conflito ou situação delicada com clientes venha à tona, pois, se isso acontece, a responsabilidade pela falta de controle da situação tende a ser do funcionário, e o risco de perder o emprego passa a ser iminente.

Com o discurso de que os sujeitos devem ser dotados de competência interpessoal e de habilidade para lidar com pessoas, a responsabilidade é sempre imputada ao indivíduo.

Assim, os indivíduos estão sempre em situação de prova, em estado de estresse, sentem queimaduras internas, tomam excitantes ou tranqüilizantes para dar conta da situação para mostrar sua "excelência” e quando esses indivíduos não são mais úteis, eles são descartados (Enriquez, 2006, p. 5).

Dessa forma, o sujeito deve estar sempre se controlando (o controle é internalizado) para que seus sentimentos e sua subjetividade não apareçam, deve estar sempre pronto para satisfazer o cliente, a chefia, a organização. Não há muita diferença, portanto, da concepção de Taylor que dizia que, com o domínio sobre o psiquismo, o indivíduo poderia contribuir para o estabelecimento de uma direção racional na organização (Enriquez, 2002). O essencial seria adaptar o homem à organização, como se o subjetivo atrapalhasse o bom andamento do trabalho e pudesse ser abolido da atividade e das relações sociais de trabalho. Por mais que o discurso coorporativo fale atualmente de seus investimentos na criatividade e na inteligência emocional dos sujeitos, o que se busca não é a liberdade de criação do sujeito, mas sim o uso de sua subjetividade como instrumento de manipulação e controle do processo de trabalho.

Analisando-se mais especificamente as organizações que se baseiam na excelência do atendimento ao cliente e na padronização dos comportamentos dos trabalhadores, constata-se que a organização do trabalho impede o uso da comunicação espontânea, da criatividade, da autonomia na resolução de problemas, expondo um ambiente de repressão, no qual as conseqüências, conforme constatado por esta pesquisa, têm se mostrado no corpo e na mente dos sujeitos: gastrites, úlceras, dores de cabeça, depressão, sensação de "estar acabado", insônia, estresse, fadiga crônica.

Nesse contexto, observa-se a insatisfação no trabalho e a de falta de reconhecimento como fatores de sofrimento e desencadeadores de doenças relacionadas ao trabalho. Dejours (1992) já afirmava que o sofrimento 
estava presente em sujeitos desmotivados com seu trabalho, não fazendo o que realmente gostam, ou seja, seu trabalho não permite uma descarga pulsional e não representa um substituto das experiências prazerosas tidas outrora. Esta insatisfação é relatada, nas entrevistas, como, por exemplo, na entrevista 21:

Você deve imaginar que os momentos de prazer não devem estar ligados ao trabalho já que eu posso falar sobre tudo... Principal do meu trabalho é a fonte de renda, independente de eu sair daqui feliz ou meio indignado, no fim do mês eu sei que o meu salário vai cair no dia " $x$ " certinho. Talvez lá uma pontinha de perspectiva de crescimento eu tenha ainda aqui mesmo.

A insatisfação, segundo os entrevistados, dificilmente é expressa por meio de palavras, sendo que os mesmos relatam que seus colegas não falam de si mesmos e que se percebe o problema somente quando a insatisfação tornou-se doença.

A falta de reconhecimento, da mesma forma que a insatisfação, é um sinal de sofrimento evidenciado pelos entrevistados, mas ao mesmo tempo, essa falta é muitas vezes identificada como uma situação "normal", com a qual o sujeito se conforma, acostumando-se com o fato de não ser elogiado, de não ter seu trabalho reconhecido. Assim, o sofrimento provocado pela falta de reconhecimento é identificado, mas em seguida é coberto por uma resposta racionalizada, como bem resume a fala do Entrevistado 2: "É assim em todas as empresas".

Dejours, Abdoucheli e Jayet (2004) afirmam que o reconhecimento confere um sentido ao trabalho que transforma o sofrimento em prazer. Está relacionado ao ganho no registro da identidade, ou seja, a atribuição de sentido em relação às expectativas subjetivas e às realizações pessoais. Acrescentam ainda que "toda a descompensação psicopatológica supõe uma hesitação ou crise de identidade" (Dejours, Abdoucheli \& Jayet, 2004, p. 74). Portanto, pode-se inferir que a falta de reconhecimento é um dos fatores de fragilização mental dos sujeitos trabalhadores, mesmo que, como defesa contra a angústia, os sujeitos identifiquem a falta de reconhecimento como algo normal.

Quando essa defesa não é mais capaz de reter a insatisfação, as saídas são o adoecimento e/ou o desligamento da organização. Além disso, o discurso organizacional tende a relacionar a satisfação única e exclusivamente com a falta de capacidade do sujeito, com sua pouca qualificação e sua falta de iniciativa. Enriquez (2006, p. 5) afirma que o advento da racionalidade instrumental, aquela que "permite o cálculo dos melhores meios e dos melhores métodos, cálculo de custos e de vantagens e que submete todo mundo ao mundo do dinheiro", sinaliza o advento de uma forma de pensamento individualista e perversa que tem como consequiência a dissolução dos vínculos sociais, a competição, o enfra- quecimento dos movimentos sociais e das lutas sindicais. Ao mesmo tempo, essa racionalidade ganha uma importância crescente nas organizações sob o comando do capital. Os indivíduos devem integrar-se e identificarse a essas organizações, colocando os valores organizacionais no lugar de seus próprios, transformando-se em seres extremamente disciplinados, fazendo-os acreditar num caminho de autonomia, sendo responsáveis por suas carreiras, por sua competência, pelos erros e fracassos organizacionais.

Assim, os sujeitos se voltam para sua própria identidade, cuidando de si mesmos e de sua vida privada. Sentindo-se sós e responsáveis, tornam-se desamparados e deprimidos, o que faz com que recorram cada vez mais às drogas para manterem-se em pé e sentirem-se produtivos (Enriquez, 2006).

\section{As Contradições da Gestão de Saúde Organizacional}

As organizações, através da área de Recursos $\mathrm{Hu}-$ manos (RH), buscam, com o emprego de novos programas de gestão (relações humanas, saúde e qualidade de vida etc.), intensificar o trabalho, aumentar a produtividade, mobilizar a criatividade e empenhar a inteligência para inovar e competir no mercado globalizado. Em entrevista, uma funcionária do RH da Vitis afirma que suas negociações com a diretoria, com relação aos programas de saúde, estão sempre embasadas em cálculos de reduções de custo e redução da rotatividade, pois somente dessa forma eles eram aprovados. Atualmente, a lógica que permeia esses programas é a de que o funcionário saudável falta menos e trabalha melhor. É importante rever esta lógica, porque a mesma deveria supor uma ação de saúde preventiva pela organização. Entretanto, a ação somente é efetiva quando os sintomas se transformam em doenças e as doenças se transformam em "redução de produtividade". Tal é a ética corporativa. Como afirma Faria (2004a, p. 164), "o lucro é a ética do capital".

Na Vitis, a gerência de RH está em constantes reuniões formais e informais com os demais gestores, buscando soluções para problemas de relacionamento interpessoal, disciplina, faltas, atrasos, demissões e avaliações. Muitas vezes, os gestores procuram essa gerência para pedir conselhos e saber como agir diante dos funcionários que fogem do padrão de comportamento.

As novas atribuições do RH das organizações contemporâneas, frente à nova realidade da globalização e da concorrência, estão relacionadas a uma gestão voltada para os resultados finais da organização, o lucro, uma parceria com outras áreas e atuação estratégica no lugar da burocrática (Cançado, Coutinho, Almeida, \& Sant'Anna, 2005). Entretanto, conforme afirmam os autores, não se detectam na prática resultados da atuação 
estratégica de RH e, além disso, essa "nova” roupagem implica novas formas de organização do trabalho, investimento na formação dos trabalhadores e novos mecanismos de controle da força de trabalho. Pesquisas têm mostrado as mudanças nas formas de organização do trabalho relativamente aos mecanismos de controle, que cada vez mais se sofisticam (Faria, 2004c).

Os programas de saúde estão dentro dessa função de tradução ideológica e mais relacionados à estratégia da competitividade da organização do que com uma real preocupação com a saúde física e mental dos integrantes da organização. De acordo com Chanlat (1996), a gestão de saúde em uma organização não se difere muito do modo de gestão geral da mesma. Dessa forma, compreende-se que os programas de saúde da Vitis estejam relacionados ao controle psicossocial, objetivando principalmente a redução de faltas, licenças e processos trabalhistas.

Segundo depoimento dos gestores entrevistados, a rotatividade e o absenteísmo dos funcionários é a situação que mais os preocupa porque há um aumento de retrabalho, necessidade de treinamento para novos contratados, perde-se o ritmo de desenvolvimento do trabalho, além de dificuldades na formação de equipes. Eles explicam a alta rotatividade pela falta de comprometimento dos trabalhadores, pela baixa escolaridade do setor operacional e pelo baixo "nível cultural" dos funcionários. Já a equipe de RH acrescenta as dificuldades na relação chefia - subordinado como um fator propiciador de demissões. Durante o ano de 2005, mais de $50 \%$ da zeladoria foi substituída, e os investimentos na área de $\mathrm{RH}$, no que se refere a programas de saúde, tiveram início justamente por causa do número bastante alto de atestados médicos e faltas que estavam interferindo nas atividades do setor.

Os atuais programas de saúde adotados pela organização estão na página seguinte:

Dos programas, o único que a maioria dos entrevistados tem conhecimento e relaciona como um programa de saúde é a ginástica laboral (GL), vista como um momento de lazer e de alívio do estresse. Nota-se que, apesar da atividade estar voltada prioritariamente para os aspectos físicos (dores e problemas nas articulações), o maior benefício para os trabalhadores é o mental.

A GLé extensiva a todos os funcionários e gestores, entretanto os últimos, em geral, sentem-se pouco a vontade com a situação. Apenas uma gestora entrevistada afirmou participar diariamente da GL e perceber resultados positivos na equipe com a sua participação. Os outros nunca participam, como afirma o Entrevistado 19: "nós deveríamos dar o exemplo, mas acaba faltando tempo, acabamos não fazendo a GL”.

Segundo os depoimentos, apesar da GL ser uma atividade obrigatória para os funcionários operacionais e administrativos, estes se apropriaram da atividade que se tornou prazerosa. $\mathrm{O}$ relato do Entrevistado 13 resume a percepção dos funcionários:

Fora a ginástica laboral, eu não tenho conhecimento de nenhum programa de saúde. A ginástica é de grande valia ... o próprio objetivo dela é que o funcionário pare, se alongue um pouco, saia da própria correria momentânea, e também o fato de você sair daquela posição: "opa deixa eu prestar atenção um pouquinho em mim”, isso também é muito saudável. É mais para alívio de estresse, pra mim pelo menos é. Aquela parada das 15 horas é importantíssima.

Quanto aos benefícios ergonômicos da GL, a professora responsável afirmou que a atividade não previne doenças osteomusculares, pois para tanto seria necessária uma frequiência muito maior do que a realizada atualmente. AGL torna-se, nesse sentido, uma atividade relacionada ao alívio da tensão, que se manifesta no corpo, e um momento de relaxamento e descontração para os funcionários, mas, ao mesmo tempo, a GL encobre a existência de outros problemas, como aponta o Entrevistado 18:

Existe alguma coisa que no meu entendimento é incipiente que é a questão da Ginástica Laboral. Na minha concepção isso ajuda, mas não resolve, o resultado pequeno é no sentido de estabelecer uma necessidade de atividade física naqueles que são extremamente sedentários. Para DORT, efetivamente, se não tiver uma constância, um aumento de freqüência, não resolve. Não é nem a questão do tempo, porque você tem que avaliar a questão ergonômica do processo do trabalho, às vezes o DORT não está nem na repetição, está no ajuste do imobiliário, no ajuste das condições, na postura, não é só uma questão de fazer atividade física e não ter DORT. Então não é só isso, o desconforto vem em relação ao processo, nessa análise mais ampliada de lesão ... Então o ajuste é muito maior pensando em saúde ... mais ampla e não pontual como é a GL. Essas doenças sempre existiram, é que a tecnologia também aumentou, antes o homem máquina era uma relação mais grosseira, hoje as máquinas tentam facilitar o trabalho do homem, mas também a competitividade faz com que algumas empresas não tenham tolerância a respeito de alguns limites do funcionário.

A essa afirmação sobre uma visão mais ampla de saúde ocupacional pode-se acrescentar ainda que, para se prevenir doenças como a LER/DORT, é necessário pensar na interação mente-corpo (Damásio, 2004), a partir da concepção de que não existe uma separação entre doenças do corpo e doenças mentais, pois elas estão constantemente em interação, gerando influências mútuas. Assim, a LER/DORT deve ser estudada como uma doença relacionada às mudanças na organização de trabalho em que se exige, conforme Giongo (2000), rapidez e eficiência incessantes, "sem perda de tempo" para pen- 
Quadro 1

Programas de Saúde Adotados pela Vitis

\begin{tabular}{|c|c|c|c|}
\hline ATIVIDADE & DESCRIÇÃO & OBJETIVO & FREQÜÊNCIA \\
\hline $\begin{array}{l}\text { Ginástica } \\
\text { laboral }\end{array}$ & $\begin{array}{l}\text { Exercícios de alongamento } \\
\text { do corpo e das articulações } \\
\text { mais utilizadas durante a } \\
\text { jornada de trabalho. }\end{array}$ & $\begin{array}{l}\text { Busca-se através da gl fomentar } \\
\text { dados para o desenvolvimento } \\
\text { de propostas de mudança de } \\
\text { estilo de vida para funcionários. }\end{array}$ & $\begin{array}{l}10 \text { minutos, de } 3 \text { a } 5 \\
\text { vezes por semana. }\end{array}$ \\
\hline $\begin{array}{l}\text { Clube da } \\
\text { caminhada }\end{array}$ & $\begin{array}{l}\text { Orientações e caminhadas } \\
\text { nos intervalos e no final do } \\
\text { expediente, como incentivo } \\
\text { ao cuidado com o corpo. }\end{array}$ & $\begin{array}{l}\text { Busca-se incentivar funcionários } \\
\text { à prática de exercícios físicos e } \\
\text { cui dados com o corpo. }\end{array}$ & $\begin{array}{l}\text { Ainda em fase de } \\
\text { implantação. }\end{array}$ \\
\hline $\begin{array}{l}\text { Esportes } \\
\text { gratuitos }\end{array}$ & $\begin{array}{l}\text { Jiu-jitsu e musculação } \\
\text { gratuitos para os } \\
\text { funcionários no horário } \\
\text { do almoço e no fim da } \\
\text { tarde. }\end{array}$ & $\begin{array}{l}\text { Busca-se incentivar funcionários } \\
\text { à prática de exercícios físicos e } \\
\text { cuidados com o corpo. }\end{array}$ & 2 vezes por semana \\
\hline $\begin{array}{l}\text { Palestras sobre } \\
\text { saúde }\end{array}$ & $\begin{array}{l}\text { Programa de palestras sobre } \\
\text { saúde para os trabalhadores, } \\
\text { sendo o primeiro tema: } \\
\text { saúde da mulher. }\end{array}$ & $\begin{array}{l}\text { Orientar e conscientizar } \\
\text { funcionários sobre os cuidados } \\
\text { com a saúde }\end{array}$ & Mensal \\
\hline $\begin{array}{l}\text { Laudos } \\
\text { ergonômicos }\end{array}$ & $\begin{array}{l}\text { Avaliações nos setores mais } \\
\text { críticos, que apresentam } \\
\text { maior incidência de } \\
\text { problemas na coluna e nas } \\
\text { articulações. }\end{array}$ & $\begin{array}{l}\text { Detectar problemas ergonômicos } \\
\text { que possam gerar doença } \\
\text { ocupacional e garantir melhores } \\
\text { condições de trabalho aos } \\
\text { funcionários. }\end{array}$ & $\begin{array}{l}\text { Realizadas em todos os } \\
\text { setores durante o ano de } \\
2006 .\end{array}$ \\
\hline $\begin{array}{l}\text { Treinamentos e } \\
\text { grupos de } \\
\text { intervenção }\end{array}$ & $\begin{array}{l}\text { Cursos de relacionamento } \\
\text { interpessoal, liderança, } \\
\text { trabalho em equipe. } \\
\text { Grupos de intervenção } \\
\text { psicológica com líderes } \\
\text { operacionais e alguns setores } \\
\text { que apresentam dificuldades } \\
\text { de relacionamento. }\end{array}$ & $\begin{array}{l}\text { Esses treinamentos e grupos } \\
\text { objetivam uma melhoria nas } \\
\text { relações verticais e horizontais } \\
\text { da cadeia hi erárquica e maior } \\
\text { eficácia da equipe de trabalho. }\end{array}$ & $\begin{array}{l}\text { Os treinamentos são } \\
\text { pontuais, realizados } \\
\text { geralmente } 1 \text { vez ao ano. } \\
\text { Os grupos são real izados } \\
\text { se manalmente ou } \\
\text { mensalmente com uma } \\
\text { equipe de psicologia. }\end{array}$ \\
\hline
\end{tabular}

sar, em que se demanda a execução de um trabalho parcelado e repetitivo, de alta vigilância e com cobrança permanente sobre a produtividade (resultados), tudo isso atado ao medo do iminente desemprego. Os trabalhadores, de acordo com sua estrutura psíquica, são mais ou menos envolvidos e alienados nessas demandas organizacionais, mas o fato é que ninguém está imune a elas (Bawa, 1997; Giongo, 2000).

Por esse motivo, é possível entender os resultados positivos da GL na Vitis, uma vez que os funcionários se apropriam dessa atividade como um momento de lazer, uma forma de descarregar tensões que sobrecarregavam sua mente e seu corpo. Assim, durante os dez minutos diários, os funcionários brincam uns com os outros, interagem, riem, fazem mímicas, massagens, enfim realizam uma atividade lúdica, na qual podem sair do comportamento rígido exigido pela instituição. Não se pode, contudo, deixar de considerar que ao mesmo tempo em que a GL auxilia no alívio das tensões e gera satisfação, do ponto de vista político e psicossocial a mesma é um importante fator de alienação (Mészáros, 2006).

A contradição entre necessidade de uma relação mais espontânea, geradora de satisfação pulsional ${ }^{6}$, marcada por uma aproximação libidinal e de laço social entre as pessoas e a alienação quanto às origens do sofrimento psíquico, fica evidente no depoimento da Entrevistada 24:

Estamos num processo de evolução, hoje eu vejo as pessoas sorrindo mais, brincando mais, no sentido sadio, não tem aquela coisa mais pesada, aquele ar pesado, estou percebendo. Chega sexta-feira e não falam "ai que semana, to cansado, estressado". Eles estão mudando as palavras: "nossa como passou rápido a semana”. Já não está mais sendo aquela coisa de "não consigo mais estar aqui dentro". Então além de trazer todo mundo muito próximo, a laboral faz isso de uma forma mais sadia, de você conseguir se divertir, dar muita risada, do outro estar fazendo um gesto e aquilo não ficar pejorativo. 
Essa aparente evolução da equipe, indicando o que seria uma satisfação no trabalho atribuída à GL em termos de relacionamento entre colegas, é um fator a ser melhor analisado porque, segundo os entrevistados, vários setores da Vitis apresentam dificuldades de relacionamento interpessoal, quer seja na relação horizontal, quer seja na relação vertical da cadeia hierárquica. Intrigas, "fofocas" e competição são freqüentes e foram mencionados pelos entrevistados como fatores desencadeadores de sofrimento. Nesse sentido, pode-se perceber que esta "magia" atribuída à GL na organização ao mesmo tempo gera satisfação pulsional, é alienante e se constitui em fator de impedimento ao sofrimento causado pelas dificuldades nos relacionamentos interpessoais.

Chama atenção igualmente que, além da vigilância da própria organização, há uma vigilância entre os próprios colegas de trabalho que controlam e delatam aqueles que fogem da regra. A cooperação é prejudicada, pois os funcionários assumem a ideologia organizacional do vigiar, identificando-se com o agressor como uma defesa contra a angústia, contra o reconhecimento do seu próprio sofrimento. O controle interpares é da ordem da vigilância, mas é também da lógica da punição pelo desencadeamento de micropenalidades ${ }^{7}$ subliminares. Os discursos revelam a insatisfação com o outro quando este não se enquadra no padrão. Este outro é tomado como detentor de privilégios se não há controle, e a organização acaba sendo percebida como não sendo uma instância de punição. Nesse caso, os chefes são identificados como não sendo suficientemente isonômicos e justos. A vigilância interpares é revelada nos discursos como uma espécie de "fazer justiça com as próprias mãos", agir em nome das atitudes unificadas e padronizadas.

Esse movimento das equipes impede uma reflexão maior sobre a própria organização do trabalho e sobre os fatores geradores de sofrimento no ambiente organizacional. Conseqüentemente, as equipes se tornam desfragmentadas, utilizando o slogan "cada um por si", fazendo com que a mobilização coletiva e um posicionamento crítico em relação às decisões organizacionais se tornem cada vez menos possíveis.

O individualismo e o silêncio dos trabalhadores fazem com que se banalize o sofrimento e se suporte decisões injustas e não-éticas no interior da organização (Enriquez, 2006). Apesar do sistema regrado e rígido de gestão da Vitis, muitas regras podem ser burladas dependendo das relações pessoais que alguns mantêm com os superiores. Evidencia-se, aqui, uma contradição entre interdição e burla, consequiências esperadas de todo o sistema de regramento rígido imposto ao conjunto dos sujeitos coletivos (Kernberg, 2000).

Baseando-nos na análise crítica dos discursos dos entrevistados, nota-se que muitos dos problemas de relacionamento existentes na organização se referem à pró- pria gestão. As entrevistas evidenciaram (a) a contradição entre uma rigidez de regras e o pessoalismo; (b) as atividades padronizadas, como possibilidades limitadas de satisfação pulsional; (c) a alienação dos funcionários às determinações da alta diretoria; (d) a falta de oportunidade de reconhecimento e (e) o funcionamento que estimula o individualismo, a competição, as intrigas e conseqüentemente a tensão emocional.

A necessidade de alívio da tensão é de tal ordem que dez minutos diários de GL podem ser tomados pelos funcionários como responsáveis por uma melhoria de relacionamento, mais aproximação das pessoas e pelo clima de cooperação.

Enriquez (2002) já afirmava sobre a impossibilidade de se unir o modelo nipônico, que privilegia os esforços coletivos e a sensação de pertencimento ao grupo, com o modelo americano, que privilegia o esforço individual e o sucesso pessoal. Quando se estimula comportamentos individualistas, como ocorre na organização estudada e de forma mais abrangente na sociedade atual, tornam-se cada vez mais raros os momentos de coletividade e cooperação.

No que se refere aos benefícios relacionados à saúde, os entrevistados citaram o plano de saúde que é administrado pela organização e está baseado em uma tabela de taxas que são pagas pelos funcionários de acordo com a faixa de salário. O plano é extensivo ao cônjuge e aos filhos. Essa taxa, de acordo com a equipe de RH e de acordo com alguns entrevistados, é muito onerosa para os funcionários da área operacional, sendo que a maioria deles não solicita o convênio, continuando a realizar seus atendimentos médicos no serviço público. Constata-se, portanto, uma reprodução da desigualdade social, pois apenas aqueles que ganham maiores salários usufruem o benefício, enquanto os que recebem menores salários são excluídos do sistema de benefícios. Mantém-se nas organizações, através de programas aparentemente racionais, um sistema de dominação e de manutenção do status quo.

Além disso, observou-se que a grande maioria dos programas e benefícios está relacionada a cuidados com o corpo: exercícios físicos, saúde física e saúde ocupacional. Mesmo que os cuidados com o corpo se reflitam no plano emocional e subjetivo do trabalhador, percebe-se que ainda é difícil para a organização introduzir a discussão e a prática de enfrentamento de assuntos diretamente vinculados à subjetividade, ao sofrimento, à dor emocional e, mais ainda, relacioná-los como fator de risco para a Saúde Mental dos trabalhadores. Apesar dos vários casos de depressão e doenças devidas ao estresse, mencionados pelo RH e pelos entrevistados e amplamente compatíveis com as estatísticas gerais divulgadas pela Fundacentro (2007), não há nenhum questionamento sobre a contribuição do trabalho para a manifestação dessas 
doenças. Assim como o comportamento, a carreira, o desempenho, os erros e as glórias dependem exclusivamente do sujeito, também o são o sofrimento e as doenças mentais, tomadas como responsabilidade e culpa única deste mesmo sujeito.

A lógica que permeia esse pensamento está baseada no que Sennet (2004) chamou de "carreiras abertas ao talento", em que o julgamento passou a ser relacionado unicamente às aptidões, às competências individuais e à motivação pessoal. Essa idéia exclui fatores extremamente importantes como o contexto econômico, social, o ambiente familiar, as diferenças cognitivas entre as pessoas e o "fator sorte". ${ }^{8}$

Assim como a competência e a formação de carreira passam a ser vistos pelo ambiente coorporativo como responsabilidade única do sujeito, o sofrimento e a doença também estão relacionados aos mais frágeis, marcando uma cisão entre os fortes e os fracos, os talentosos e não talentosos, os potenciais e não potenciais. Diante disso, o silêncio e a busca exclusiva por soluções rápidas (medicamentos) têm dominado o "mundo" coorporativo, especialmente favorecido pela evolução científica da farmacologia.

Assim, o silêncio do sofrimento (Dejours, 2001) está relacionado com a lógica do individualismo, tanto em gestores quando em funcionários operacionais. Uma vez que a doença mental, como atesta Foucault (2000), está sempre acompanhada de valores e julgamentos de uma dada cultura, nas organizações a mesma está relacionada ao fracasso, a um indivíduo com o qual não se pode contar, alguém frágil, "problemático". Assim, os sujeitos se calam, pois a exposição dessa identificação com o fracassado suscita angústia e temor de perder o lugar conquistado na organização.

Uma outra solução para justificar o sofrimento e o adoecimento dos trabalhadores é torná-los uma manifestação unicamente química do organismo, isentando todos, o sujeito, a organização social e a sociedade de qualquer tipo de responsabilidade. Essas são as justificativas que mascaram e simplificam o mal-estar do homem, as dores, as falhas, as dificuldades do sujeito diante de organizações baseadas na qualidade total, na falha zero, na excelência. Tudo precisa ser limpo, organizado, resolvido. Nesse sentido, o sofrimento, a angústia, a doença mental são considerados "sujeiras a serem limpas", e não considerados como afetos e manifestações intrínsecos à condição humana que necessitam ser compreendidos e tratados em toda sua complexidade.

Torna-se difícil o questionamento e a reflexão em uma sociedade que busca cobrir todas as faltas e falhas com soluções rápidas e instantâneas para todos os males através apenas do consumo de medicamentos, ou do uso de objetos, como se realmente se pudesse comprar a felicidade.
O laço social, o vínculo duradouro e o aprofundamento do conhecimento das idéias, dos fenômenos, tornam-se "perda de tempo". Assim, como afirma Sennet (2004, p. 101):

As novas formas de trabalho requerem pessoas que
consigam passar facilmente de uma tarefa para ou-
tra, de um emprego para outro, de um lugar para
outro. ... A capacidade de aprender coisas novas
com rapidez passa a ser mais valorizada do que a
capacidade de se aprofundar ainda mais em um
problema de dados existentes.

Se o superficial tem dominado o ambiente coorporativo, os programas relacionados à saúde do trabalhador seguem esse mesmo caminho. São intervenções de caráter pontual, paliativo, sem uma investigação profunda das causas de sofrimento e doenças e sem o engajamento e apoio real dos principais dirigentes. Os funcionários do RH (psicólogos, assistentes sociais, administradores) permanecem em uma posição contraditória, na qual, ao mesmo tempo em que há uma sensibilização por parte de alguns deles para os problemas organizacionais e o sofrimento dos trabalhadores, os mesmos acabam atuando como executores das decisões baseadas em programas gerencialistas que intensificam o controle psicossocial, com poucos resultados efetivos e duradouros para os trabalhadores. Impulsionados pelo medo de sua própria demissão, os gestores e profissionais de RH deixam seu pensamento crítico de lado, conforme mencionado pelo Entrevistado 19:

A gente entra como negociador, tem coisa que dá
para negociar, outras não. Então cada caso é um
caso e tem negociações que a gente consegue aten-
der dependendo do tipo de necessidade, se a em-
presa vê se vale a pena, se ela vai ter um beneficio
ou não. Você entra como um negociador entre o
funcionário e a empresa e em muitos casos a gente
tem sucesso. Já se entrou em conflito, mas aqui o
que vale é a empresa, manda quem pode, obedece
que tem juízo.

Os laudos ergonômicos são um exemplo claro dessa contradição. Esta atividade, cujo objetivo divulgado foi o de melhorar as condições de trabalho e a saúde ocupacional apresenta, por trás dessa primeira justificativa, o objetivo de ser um documento de defesa jurídica em caso de processo trabalhista. Além disso, com o laudo, as queixas posteriores e os atestados médicos relacionados a problemas de LER/DORT não apresentariam mais razão para existir, pois a organização apresentou todas as condições ergonômicas de trabalho.

Entretanto, Dejours (1992) afirma que não é simples prever os efeitos de uma "melhoria objetiva" das condições de trabalho e, por esse motivo, torna-se importante a escuta da "vivência subjetiva coletiva" dos trabalhadores. Além disso, a avaliação ergonômica é limita- 
da, pois consegue beneficiar apenas parcialmente os trabalhadores, sendo que o alívio da carga ainda permite a intensificação da produtividade. "a intervenção ergonômica não atinge a situação de trabalho em profundidade, pois, ela permanece aquém da organização do trabalho" (Dejours, 1992, p. 56). Assim, enquanto a ergonomia não trouxer satisfação em termos de conteúdo significativo do trabalho, adequando o conteúdo ergonômico com a personalidade do sujeito trabalhador, o alívio será limitado.

Essas contradições que estão presentes em toda gestão de RH relacionada à Saúde do Trabalhador podem ser resumidas na fala do Entrevistado 19:

Até o nosso RH deveria cuidar mais disso [está falando do acompanhamento das pessoas que adoecem]. A gente não procura saber se a pessoa está precisando de alguma coisa, se aconteceu alguma coisa, só fica sabendo quando ela volta. Deveria ter um acompanhamento, mas não tem, só é feito um acompanhamento legal para você proteger a própria empresa, mas não é preocupado com a pessoa.

Há um esforço para que as contradições no discurso organizacional sejam ocultadas, como o são as falhas, os conflitos e os disfarces que acompanham as relações de poder e de controle (Faria, 2004c).

\section{Considerações Finais}

O presente artigo teve como objetivo principal identificar e analisar as contradições e os limites na Saúde Mental no trabalho através de uma análise crítica das estratégias organizacionais de promoção de saúde do trabalhador.

Esta pesquisa constatou, através da escuta dos trabalhadores entrevistados, que os sinais mais subjetivos (angústia, medo, insatisfação) constituem a semente, o germe de manifestações de doenças mentais ou psicossomáticas. Estas últimas podem ser entendidas como um estágio avançado do sofrimento, que não pode mais ser calado, pois os atestados, as faltas e a diminuição de produtividade delatam que algo não vai bem com a saúde de determinado trabalhador.

Foram mencionadas, durante as entrevistas, várias manifestações de sofrimento, dentre as quais cabe destacar oito: (a) quadros de insônia, (b) ansiedade crônica, (c) fadiga, (d) estresse, (e) depressão, (f) sensação de estar esgotado, (g) dores nas articulações e (h) dores de cabeça. Os sujeitos relacionaram o trabalho como um fator que pode desencadear, influenciar ou piorar uma doença mental ou psicossomática e, entre os fatores da organização do trabalho propiciadores deste quadro, mencionaram: (a) as condições físicas de trabalho inadequadas, (b) relacionamento difícil com a chefia e com subordinados, (c) as fofocas, (d) os clientes, (e) a insatis- fação com o trabalho, (f) a falta de reconhecimento, (g) a pressão no trabalho, (h) o excesso de responsabilidades, (i) a sensação de ser vigiado e (j) as orientações contraditórias para a execução da tarefa.

Apesar dessa percepção, não há nenhum tipo de mobilização dos trabalhadores em prol de uma organização do trabalho com menos riscos para a Saúde Mental. O medo de perder o emprego e o lugar conquistado na organização (na medida em que o sujeito, além do vínculo objetivo, estabelece um vínculo subjetivo com a organização $)^{9}$ constitui um dos fatores de passividade e silêncio dos trabalhadores. Quando o sofrimento não é falado e compartilhado pelos sujeitos, tem maior probabilidade de se tornar uma doença individual, com uma solução também individual: o afastamento, o desligamento ou o medicamento como possibilidade de se manter trabalhando.

Exigem-se, na Vitis, padrões de comportamento e de atendimento, nos quais os sujeitos apresentam dificuldade de expressar sua singularidade atrás dos uniformes, das frases prontas, dos procedimentos padronizados. Mais uma vez, a exemplo da Vitis, o que ocorre nas organizações é reflexo da sociedade que busca a uniformidade, em que todos devem ser iguais, consumir as mesmas coisas. Quando surge a diferença, eclode o ódio, o preconceito, a exclusão e a violência (Cavalleiro, 2001; Faria \& Meneghetti, 2007; Kailin, 2002).

Como nas organizações, e particularmente na Vitis, o controle nunca é total, os conflitos emergem e se materializam através da não adesão de todos os sujeitos a todas as regras organizacionais, do absenteísmo, dos "boicotes" às ordens impostas, das reclamações, do sofrimento expresso, das doenças físicas e mentais. As contradições e conflitos, quando não podem ser expressos por meio de palavras, são expressos através dos atos, do individualismo e da agressividade.

Apesar do discurso do trabalho em equipe, as organizações capitalistas estimulam o valor individual em detrimento do coletivo, sob a ideologia da livre competição entre os sujeitos autônomos, em busca do lucro e do interesse pessoal. O novo ideal do indivíduo bem sucedido que mantém um lugar privilegiado na hierarquia social apresenta conseqüências para a subjetividade do sujeito, cada vez mais solitário, temendo a identificação com o fracassado, não se sentido construtor da história e cada vez mais recorrendo a medicamentos e drogas para se manter, dormir, acordar, sentir-se mais alegre.

As contradições na gestão de saúde da Vitis são evidenciadas na medida em que os benefícios e programas de saúde estão relacionados mais ao sistema de controle da organização do que a uma real preocupação com a saúde do trabalhador, buscando cobrir "as falhas" desse sistema e atuando em cima dos efeitos da organização do trabalho. Na análise da gestão de Saúde da Vitis podese constatar que a motivação para a promoção de pro- 
gramas de saúde surgiu devido ao índice crescente de absenteísmo, aos atestados médicos, à alta rotatividade de alguns setores e conseqüentemente a uma diminuição da produtividade.

Dos programas e benefícios listados pela equipe RH com relação à gestão de saúde, a Ginástica Laboral (GL) foi o mais lembrado pelos entrevistados. A GL foi elaborada, segundo os responsáveis pela área de $\mathrm{RH}$, com o intuito de proteger a organização contra acusações do surgimento de doenças osteomusculares em decorrência do trabalho.

Entretanto, a atividade foi apropriada pelos funcionários como "válvula de escape" da pressão e da repetição do dia a dia, promovendo um alívio coletivo. Contraditoriamente, não apenas resultou em alívio de sofrimento, como introduziu um aditivo ao processo de alienação.

A gestão de saúde da organização, assim como sua gestão geral, atua com intervenções pontuais e paliativas, isentando-se de realizar uma real análise organizacional com suas falhas, seus conflitos, suas contradições. Os programas de saúde, inclusive a GL, "tamponam" as falhas da relação indivíduo-organização, ao tempo em que não permitem uma análise mais profunda dos fatores que geram o sofrimento e o adoecimento do trabalhador.

Esse estudo não se encerra com estas considerações finais, mas abre espaço para outros questionamentos em relação à Saúde Mental no Trabalho e para novas pesquisas. O desenvolvimento dessa mesma pesquisa em outras organizações com o intuito de comparar os dados obtidos é recomendável. As manifestações recentes de adoecimento como a LER/DORT, a síndrome de burnout, o estresse relacionados ao trabalho e outras manifestações de sofrimento podem e devem ser aprofundadas em outros estudos, não apenas como interesse acadêmico, mas como crítica à gestão das organizações contemporâneas e como contribuição ao entendimento e às ações em favor da Saúde Mental do trabalhador.

\section{Notas}

*Agradecimento à CAPES pelo bolsa de estudo concedida durante a realização do mestrado da autora Amanda de Vasconcelos

${ }^{1}$ Alguns autores (Codo, 2004; Jaques, 2003; Vasques-Menezes, 2004) discordam das análises de Dejours quando este afirma que apenas a infância pode ser portadora da doença mental e de que não se poderia fazer relação direta entre uma ocupação profissional e o surgimento de uma doença. Codo (2004), por exemplo, sustenta que nenhum evento apresenta uma relação linear com a psicopatologia ou com a "normalidade". Em sua perspectiva, alguns eventos aumentam a probabilidade de ocorrerem manifestações psicopatológicas. Dessa forma, investiga-se a probabilidade que um trabalho tem de desencadear alguma psicopatologia. Os fatores de risco para a instalação de uma psicopatologia seriam "todos aqueles que são importantes para a construção da personalidade e da identidade, ou ainda da interação entre elas. A sexualidade, a infância, a escola, os gru- pos na adolescência, o gênero, o trabalho" (Codo, 2004, p. 15).

${ }^{2}$ A organização e os entrevistados não serão divulgados a pedido. Alguns entrevistados não fizeram restrições a este respeito. Optou-se, neste caso, por dar o mesmo tratamento às diferentes situações.

${ }^{3}$ Izabel Magalhães sugere, muito apropriadamente, que "Critical Discourse Analysis" seja traduzida por "Análise de discurso crítica", pois a análise de discurso é uma área com forte tradição no Brasil (Magalhães, 2005).

${ }^{4}$ A sigla LER (Lesão por Esforço Repetitivo) está acompanhada de um movimento cultural, político, reivindicativo, de reação a um contexto, podendo ser definido como um fenômeno social que transcende os limites da área médica, necessitando de análises psicológicas, sociológicas e antropológicas. Apresenta uma historicidade importante e foi substituída por DORT (Doenças Osteomusculares Relacionadas ao Trabalho) pela burocracia da Previdência Social, despolitizando a trajetória da LER como doença do trabalho. Entretanto, considerando o uso da sigla DORT pelo Ministério da Saúde (Brasil, 2001) como aquela oficialmente aceita, utilizar-se-á neste trabalho a expressão LER/DORT.

${ }^{5}$ No caso aqui estudado, "cliente" é como se considera aquele que adquire os serviços (o aluno, principalmente), embora a IES tenha um discurso oficial contrário ao uso deste termo na área acadêmica. Não seria de todo incorreto inferir que um mesmo sujeito seja aluno, quando nas atividades acadêmicas, e cliente, quando demanda serviços de apoio (documentos, declarações, matrículas etc.).

${ }^{6}$ É o prazer do trabalhador resultante da descarga de energia psíquica que a tarefa autoriza e que corresponde a uma diminuição da carga psíquica do trabalho. A carga psíquica pode ser entendida como o subemprego de aptidões psíquicas, fantasmáticas ou psicomotoras. A energia psíquica se acumula e torna-se fonte de tensão e desprazer, gerando por conseguinte a fadiga e a propensão à psicopatologia (Dejours, Abdoucheli, \& Jayet, 1994).

${ }^{7}$ Os conceitos de vigiar, punir e micropenalidades são os propostos por Foucault (1977).

${ }^{8}$ A rigor não se trata de sorte, mas de oportunidades apresentadas aos sujeitos e de suas escolhas. Oportunidades estas que não são casuais, mas ligadas à isenção dos sujeitos nas relações sociais e de produção e nas redes de relacionamentos daí recorrentes.

${ }^{9}$ Ver sobre isto em Faria e Schmitt (2007).

\section{Referências Bibliográficas}

Bawa, J. (1997). Computador e saúde. São Paulo: Summus.

Borges, L. O. \& Angolo, J. C. T. (2003). Estratégias organizacionais na promoção da saúde mental do indivíduo podem ser eficazes? In M. G. Jacques \& W. Codo (Orgs.), Saúde mental e trabalho: leituras (2 ed., pp. 271-295). Petrópolis, RJ: Vozes.

Brasil. Ministério da Saúde. (2001). Manual de procedimentos para serviço da saúde: doenças relacionadas ao trabalho. Série A - Normas e Manuais Técnicos, n. 114. Brasília: Ministério da Saúde.

Bruyne, P., Herman, J., \& Schouteete, M. (1977). Dinâmica da pesquisa em ciências sociais. Rio de Janeiro: Francisco Alves.

Cançado, V. L., Coutinho, P. T., Almeida, M. G., \& Sant'Anna, A. S. (2005, setembro). Novos papéis de Recursos Humanos: velhas fórmulas em novas embalagens? [CD-ROM]. In ANPAD (Org), 
XXIX Encontro Anual da ANPAD. Brasília: ANPAD.

Cavalleiro, E. (Org.). (2001). Racismo e anti-racismo na educação. São Paulo: Summus.

Chanlat, J. (1996). Modos de gestão, saúde e segurança no trabalho. In E. Davel \& J. Vasconcelos (Orgs.), Recursos Humanos e subjetividade (pp. 118-129). Petrópolis, RJ: Vozes.

Codo, W. (2004). Psicopatologia do trabalho. In W. Codo (Org.), $O$ trabalho enlouquece? Um encontro entre a clínica e o trabalho (pp. 11-22). Petrópolis, RJ: Vozes.

Damásio, A. R. (2004). O erro de Descartes: emoção, razão e o cérebro humano. São Paulo: Cia das Letras.

Dejours, C. (1992). A loucura do trabalho: estudo de psicopatologia do trabalho ( $5^{\text {a }}$ ed.). São Paulo: Cortez-Oboré.

Dejours, C. (2001). A banalização da injustiça social ( $3^{\mathrm{a}}$ ed.). Rio de Janeiro: FGV.

Dejours, C., Abdoucheli, E., \& Jayet, C. (1994). Psicodinâmica do trabalho: contribuições da Escola Dejouriana à análise da relação prazer, sofrimento e trabalho. São Paulo: Atlas.

Dejours, C., Abdoucheli, E., \& Jayet, C. (2004). Da psicopatologia à psicodinâmica do trabalho. In S. Lancman \& L. I. Sznelwar(Orgs.), Christophe Dejours: da psicopatologia à psicodinâmica do trabalho (pp. 70-75). Rio de Janeiro: Ed. Fiocruz.

Enriquez, E. (2002). O indivíduo preso na armadilha da Estrutura Estratégica. In F. C. P. Motta \& M. E. Freitas (Orgs.), Vida psíquica e organização (pp. 23-40). Rio de Janeiro: FGV.

Enriquez, E. (2006). O homem do século XXI: sujeito autônomo ou indivíduo descartável. Revista de Administração de Empresas. RAEeletrônica, 5 (1). Acesso em 14 de dezembro, 2008, em http:// www.rae.com.br/eletronica

Fairclouch, N. (2001). Discurso e mudança social. Brasília: Ed. UNB.

Faria, J.H. (2004a). Economia política do poder-fundamentos. Curitiba: Juruá.

Faria, J. H. (2004b). Economia política do poder - uma crítica da teoria geral da administração. Curitiba: Juruá.

Faria, J. H. (2004c). Economia política do poder - as práticas do controle nas organizações. Curitiba: Juruá.

Faria, J. H. \& Schimitt, E. C. (2007). Indivíduo, vínculo e subjetividade. In J. H. Faria (Org.), Análise crítica das teorias e práticas organizacionais (pp. 23-44). São Paulo: Atlas.

Faria, J. H. \& Meneghetti, F. K. (2007). A Instituição da violência nas relações de trabalho. In J. H. Faria(Org.), Análise crítica das teorias e práticas organizacionais (pp. 278-298). São Paulo: Atlas.

Flick, U. (2007). Uma introdução à pesquisa qualitativa. Porto Alegre: Bookman.

Fundacentro. (2007). Estatísticas sobre acidentes e doenças do trabalho. Acesso em 29 de novembro, 2007, em http:// www.previdenciasocial.gov.br

Foucault, M. (1977). Vigiar e punir. Petrópolis, RJ: Vozes.

Foucault, M. (2000). Doença mental e psicologia. Rio de Janeiro: Tempo Brasileiro.

Giongo, A. L. (2000). Da organização do trabalho hoje às doenças ocupacionais: o que éLER. In A. Jerusalinsky, A. C. Merlo, \&A. L. Giongo (Orgs.), O valor simbólico do trabalho (pp. 265-270). Porto Alegre: Artes e Ofícios.

Gorenstein, L. \& Carneiro, M. L. T. (Orgs.). (2006). Ensaios sobre a intolerância ( $2^{\mathrm{a}}$ ed.). São Paulo: Associação Editorial Humanitas.

Grubits, S. \& Noriega, J. A. (Orgs.). (2004). Métodos qualitativos: epistemologia, complementariedades e campos de aplicação. São Paulo: Vetor.

Hallack, F. S. \& Silva, C. O. (2005). A reclamação nas organizações do trabalho: estratégia defensiva e evocação do sofrimento. Psicologia \& Sociedade, 17(3), 67-72.

Jacques, M. G. (2003). "Doenças dos nervos": uma expressão da relação entre saúde/doença mental. In: M. G. Jacques \& W. Codo (Orgs.), Saúde mental \& trabalho: leituras (2 ed., pp. 98-111). Petrópolis, RJ: Vozes.

Kailin, J. (2002). Antiracist Education: From theory to practice. Maryland: Rowman \& Littlifield.

Kernberg, O. F. (2000). Ideologia, conflito e liderança em grupos e organizações. Porto Alegre: Artes Médicas.

Le Guillant, L. (1954). Introduction à une psychopathologie sociale. L'évolution psychiatrique, 1, 1-52

Magalhães, I. (2005). Introdução: a análise de discurso crítica. Delta, 21. Acesso em 13 de dezembro, 2008, em http://www.delta.pucsp.br

Mello, O. (2008, 27 de abril). O mal-estar da civilização. Jornal Valor Econômico, pp. 20-21.

Mészáros, I. A. (2006). Teoria da alienação em Marx. São Paulo: Boitempo.

Rey, F. G. (2005). Pesquisa qualitativa e subjetividade: os processos de construção da informação. São Paulo: Thomson.

Sivadon, P. (1952). Psychopathologie du travail. L'évolution psychiatrique, 3, 441-474.

Sivadon, P. (1957). Psychiatrie du travail. In H. Desoille (Org.), Cours de medicine du travail (Tome 2, pp. 405-420). Paris: Lefrançois.

Sennet, R. (2004). Respeito: a formação do Caráter em um mundo desigual. São Paulo: Record.

Vasques - Menezes, I. (2004). Por onde passa a categoria trabalho na prática terapêutica? In W. Codo (Org.), O trabalho enlouquece? (pp. 23-52). Petrópolis, RJ: Vozes.

Yin, R. K. (1987). Case study research (7th ed.). Beverly Hills: Sage Publications.

Amanda de Vasconcelos é Psicóloga e Especialista em Saúde Mental, Mestre em Administração (UFPR). Atualmente é Professora dos cursos de Administração e Psicologia do Centro Universitário Positivo - UnicenP. Endereço para correspondência: UNICENP - Curso de Administração. Rua Professor Pedro Viriato Parigot de Souza, 5.300. Curitiba, PR, Brasil. CEP 81280-330 Email: avamanda@yahoo.com.br

José Henrique de Faria é Professor Titular do Programa de Mestrado Interdisciplinar em Organizações e Desenvolvimento - FAE/Centro Universitário, Professor Sênior da Universidade Federal do Paraná, Economista (FAE-PR), Mestre em Administração (UFRGS), Doutor em Administração (FEA-USP) e Pós Doutor em Relações do Trabalho (University of Michigan - ILIR). Endereço para correspondência: UFPR - Depto. De Administração Geral e Aplicada. Av. Pref. Lothário Meissner, 3400. Sala 22. Jardim Botânico. Curitiba, PR, Brasil. CEP 80210-170 E-mail:jhfaria@gmail.com.br

Saúde mental no trabalho: contradições e limites

Amanda de Vasconcelos e José Henrique de Faria

Recebido: 12/04/2007

$1^{\text {a }}$. Revisão: $13 / 06 / 2008$

Aceite final: 13/06/2008 